Available online on 15.07.2020 at http://ujpr.org
Universal Journal of Pharmaceutical Research
An International Peer Reviewed Journal
Open access to Pharmaceutical research

\title{
THROMBOPROPHYLAXIS IMPACT IN PATIENTS UNDERGOING MAJOR ORTHOPEDIC SURGERY IN SUDAN
}

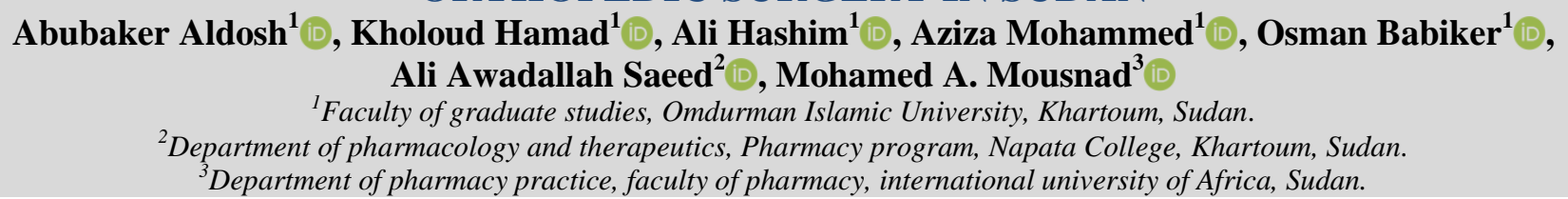

\section{ABSTRACT}

Objective: Venous thromboembolism is an important complication of major orthopedic surgery. The aim of present study was to investigate the efficacy of the currently used thromboprophylaxis protocol, determine the incidence of VTE post operatively and the risk factors behind it in patients undergoing major orthopedic surgery.

Methods: A retrospective descriptive study for 403 patients underwent major orthopedic surgery from July 2013 to July 2014 in main hospitals in Khartoum state where major orthopedic surgery performed. Data were collected using observation checklist and analyzed using SPSS version 22 to study the association between the type of surgery, patient's risk factors, choice and duration of thromboprophylaxis and development of VTE after major orthopedic surgery.

Results: Total 403 patients were incorporated the study, 2.73\% were diagnosed with DVT developed within 5 days post operatively. $1.64 \%$ of the patients not received any type of thromboprophylaxis, $0.27 \%$ wore compression stocking. Pharmacological methods were used in the rest of the patients, $96.72 \%$ administered to them enoxaparine.

$75.95 \%$ of the patients presented with one or more than one risk factors for VTE other than the orthopedic surgery. $4 \%$ of patients received thromboprophylaxis for more than 14 days while $96 \%$ received it for 3-5 days. The incidence of DVT was higher in diabetic patients $(p=0.03)$ and hypertensive $(p=0.046)$ who aged $\geq 60$ years.

Conclusion: Results showed that VTE was a significant complication of major orthopedic surgery, despite the use of thromboprophylaxis and the incidence was $2.73 \%$ in our study.

Keywords: Deep-vein thrombosis, incidence, orthopedic surgery, venous thromboembolism.

Article Info: Received 26 April 2020; Revised 1 June; Accepted 1 July, Available online 15 July 2020

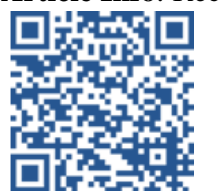

Cite this article-

Aldosh A, Hamad K, Ali H, Mohammed A, Babiker O, Saeed AA. Thromboprophylaxis impact in patients undergoing major orthopedic surgery in Sudan. Universal Journal of Pharmaceutical Research 2020; 5(3):44-47.

DOI: https://doi.org/10.22270/ujpr.v5i3.415

Address for Correspondence:

Ali Awadallah Saeed, Department of pharmacology and therapeutics, Pharmacy program, Napata College, Khartoum, Sudan. Tel: (+249) 0912320825; E-mail: $m$ abdalaziz@yahoo.com

\section{INTRODUCTION}

Due to immobility and mechanical vascular damage patients with major surgical procedures be in a hypercoagulable state by altering hemodynamic stasis from the operative intervention. Owing to the physical and mechanical impact on the venous system of the lower limb, orthopedic procedures such as hip fracture surgery (HFS), total hip replacement (THR) and total knee replacement (TKR) are thought to be particularly problematic. Other types of major orthopedic surgery for spinal or upper limbs are not contributed to thrombogenic risk $^{1,2}$. The thromboembolic risk influenced by type of anesthesia, as general anesthesia increase the thromboembolic risk and in the other side inappropriate administration time of antithrombic drugs with spinal anesthesia exposed the patients to risk of hematoma ${ }^{3}$. High risk of venous thromboembolism increased by clinical or patient independent factors include a history of previous Deep Venous Thrombosis (DVT), age, use of oral contraceptives, pregnancy, and comorbidity, cancer, myocardial infarction, and stroke. Higher rate of DVT in orthopedic surgery if no prophylaxis is given occur when a combination of predisposing surgical and patient risk factors are available ${ }^{4,5}$. Mechanical, pharmacologic, and/or ancillary means can be used for thromboprophylaxis. Anti- embolism stockings, foot impulse devices, and intermittent pneumatic compression devices (IPC) are examples of mechanical methods. Using Low Molecular Weight Heparin (LMWH), unfractionated 
heparin (UFH), and other anticoagulants (such as Vitamin K antagonists (VKAs), apixaban, dabigatran, fondaparinux, and rivaroxaban) as pharmacological VTE prophylaxis depending on patient medical state and presence of contraindications. Early mobilization and prevention of dehydration is the ancillary methods. Pharmacological thromboprophylaxis with an IPC device for THR or TKR, with LMWH being preferred as the first-line option over other pharmacological agents as recommended by the American collage of chest physician ACCP guidelines in February 2012. Extending the duration of thromboprophylaxisis the recent updated ACCP guidelines for 28 to 35 days following THA or hip fracture surgery where the risk for venous thromboembolism persists for up to 3 months after surgery. Preventing venous thromboembolism in major orthopedic surgery done by using low molecular weight heparin as extendedduration thromboprophylaxis (up to 6 weeks) is effective $^{6}$. The national institute of health and care excellence NICE guidelines emphasizes mechanical intervention prior to the surgery at admission as well as pharmacological prophylaxis after THR (for 28-35 days) and TKR (for 10-14 days). Despite the recommendations of current guidelines and availability of effective thromboprophylaxis medications, it is inadequately used in clinical practice especially in major orthopedic surgery (THA, TKA, or hip fracture surgery) even with no presence of contraindications which contributes to observation of many cases developing DVT that necessitate a long term expensive treatment $^{7}$. The objective of current study was to investigate the efficacy of the currently used thromboprophylaxis protocol and determine the incidence of VTE post operatively and the risk factors behind it in patients undergoing major orthopedic surgery.

\section{METHODS}

\section{Study design}

Retrospective descriptive study for 403 patients from July 2013 to July 2014 using records obtained from health services administrative databases. The demographic database provides information on age, weight and sex. Procedure instruction provides information on type of surgery, type of anesthesia used and onset of thromboprophylaxis initiation. Patient record provides information about independent risk factors, age, obesity, pregnancy, comorbidity, cancer, previous DVT, myocardial infarction and stroke. Follow up records provides information on drugs used for thromboprophylaxis, the dose, administration, duration of thromboprophylaxis and clinical monitoring for signs and symptoms of VTE.

\section{Study area}

Main hospitals in Khartoum state where major orthopedic surgery performed: ShargAlnail Hospital, Saheron Hospital, Omdurman Military Hospital, Alribatteaching hospital and Bahri teaching hospital

\section{Data collection and analysis}

The data were collected by using observation checklist and analyzed using the Statistical Package for the Social Sciences for Windows (SPSS) version 22 to study the association between the type of surgery, patient's risk factors, choice and duration of thromboprophylaxis and development of VTE after major orthopedic surgery.

Table 1: Distribution of study sample according to hospital.

\begin{tabular}{llc}
\hline Hospital & Frequency & $\begin{array}{c}\text { Percent } \\
(\%)\end{array}$ \\
\hline Sherq Alneel & 131 & 32.5 \\
Bahry & 60 & 14.9 \\
Alshorta & 46 & 11.4 \\
AlslahAltiby & 118 & 29.3 \\
Sahiroon & 48 & 11.9 \\
Total & 403 & 100.0 \\
\hline
\end{tabular}

\section{RESULTS}

The data of 403 patients were assessed; the information was collected from five hospitals in which the major orthopedic surgery performed (Table 1). The percentage of knee arthroplasty, hip arthroplasty, femur fracture and pelvic fracture repair were $28.3 \%, 16.9 \%$, $42.9 \%$ and $11.9 \%$ respectively. The mean age of the patients was $55.36 \pm 18.77$ years. Male encountered 63 $\%$ while female were $37 \%$. $9 \%$ of the patients were administered to them general anesthesia where as $91 \%$ were treated with combined spinal-epidural anesthesia (Table 2).

Table 2: Demographic data, type of surgery, and type of anesthesia used in the patients $(n=403)$.

\begin{tabular}{lc}
\hline Variable & Result \\
\hline Age (year) & $55.36 \pm$ \\
& 18.77 \\
\hline Gender & \\
Male & $254(63.0 \%)$ \\
Female & $149(37.0 \%)$ \\
\hline Type of surgery & \\
Hip arthroplasty & $116(28.8 \%)$ \\
Knee arthroplasty & $114(28.3 \%)$ \\
Femur fracture & $173(42.9 \%)$ \\
repair & \\
\hline \multicolumn{2}{l}{ Type of anesthesia } \\
General \\
Combined \\
\hline \multicolumn{2}{c}{$*$ Value expressed as mean \pm SD. }
\end{tabular}

Six patients $(1.64 \%)$ not received any type of thromboprophylaxis, $1(0.27 \%)$ wore compression stocking only without presence of a contraindication to the pharmacological thromboprophylaxis. Pharmacological methods were used in the rest of the patients, $354(96.72 \%)$ patients enoxaparine was administered, tinzaparin used in $2(0.55 \%)$, aspirin in 1 $(0.27 \%)$ and $2(0.55 \%)$ received aspirin plus enoxaparin. The dose of enoxaparin used in these cases was $40 \mathrm{mg} /$ day subcutaneously (SC), tinzaparin 4500 IU administered SC per day and $100 \mathrm{mg}$ aspirin orally per day. The prophylaxis started before surgery with no available records about the exact time of administration. There were no cases reported with bleeding complications due to Thromboprophylaxis.

Total $306(75.95 \%)$ of patients presented with beside the orthopedic surgery one or more risk factor for VTE. Additional risk factors for VTE are included in (Table 
3). Thromboprophylaxis for more than 14 days was implemented in $13(4 \%)$ while in $349(96 \%)$ of the cases was administered for short term, most of them until patient discharged (for 3-5 days). Of the 403 patients, 11(2.73\%) were diagnosed with DVT.

Table 3: Distribution of potential risk factors other than major orthopedic surgery for venous thromboembolism.

\begin{tabular}{lc}
\hline Additional risk factors & $\begin{array}{c}\text { Study sample } \\
(\mathbf{n = 4 0 3})\end{array}$ \\
\hline Age $\geq 40$ years & $278(69 \%)$ \\
Previous history of DVT & $11(2.7 \%)$ \\
Malignancy & 0 \\
Hormone therapy & $3(0.7 \%)$ \\
Pregnancy & $1(0.2 \%)$ \\
\hline Comorbidity & $83(20.6 \%)$ \\
Diabetes mellitus & $118(29.3 \%)$ \\
Hypertension & $5(1.20 \%)$ \\
Dyslipidemia & $5(1.20 \%)$ \\
Stroke & 0 \\
Myocardial infarction & $12(3.00 \%)$ \\
Others* & \multicolumn{2}{c}{$*$ sickle cell disease or Hyperthyroidism }
\end{tabular}

Majority of the patients who had DVT, it was developed within the first 5 days postoperative. The time for onset of DVT in the patients is shown in Table 4.

Table 4: Time per day for the onset of deep vein thrombosis in the study sample.

\begin{tabular}{lc}
\hline \multicolumn{2}{c}{$\begin{array}{c}\text { Statistics of (Onset of } \\
\text { thrombosis post operatively) }\end{array}$} \\
\hline Number of patients & 11 \\
Mean & 5.8182 \\
Median & 5.0000 \\
Std. Deviation & 2.40076 \\
Minimum & 3.00 \\
Maximum & 10.00 \\
\hline
\end{tabular}

Majority of patients (10) who developed DVT were aged $\geq 60$ years, one patient who is 18 years had a sickle cell disease. No significant differences were found regarding the gender or the type of the surgery in the group of patients who developed DVT $(p>0.05)$.

Table 5: Factors influencing the development of thromboembolism in patients undergoing major orthopedic surgery.

\begin{tabular}{|c|c|c|}
\hline Factor & At 95\% Cl. & $\boldsymbol{P}$ \\
\hline Type of anesthesia & & \\
\hline General anesthesia & $-0.721-$ & 0.012 \\
\hline Age $\geq 60$ years & $-1.074-$ & 0.040 \\
\hline $\begin{array}{l}\text { Duration of } \\
\text { Thromboprophylaxis }< \\
14 \text { days }\end{array}$ & $-1.185-$ & 0.027 \\
\hline $\begin{array}{l}\text { Additional risk } \\
\text { factors } \\
\text { Diabetes mellitus } \\
\text { Hypertension }\end{array}$ & $\begin{array}{c}-0.650- \\
-0.610-\end{array}$ & $\begin{array}{c}0.03 \\
0.046\end{array}$ \\
\hline
\end{tabular}

The analysis revealed that the patients received general anesthesia $(p=0.012)$ were at a greater risk for the development of DVT than those who had spinal anesthesia. The incidence of DVT was higher in diabetic patients $(p=0.03)$ and hypertensive ( $p$ -
$=0.046)$. However, the incidence of thromboembolism in patients with a previous history of DVT, stroke, hormone replacement therapy or dyslipidemia was not significantly higher than in other patients $(p>0.05$ for all). $81.8 \%$ of the patients developing DVT received the thromboprophylaxis for 3 days with no significance difference regarding the choice of drug. One patient not received the therapeutic dose of DVT was died as a result of thromboembolism, leading to a mortality rate of $0.24 \%$.

\section{DISCUSSION}

The incidence of thromboembolism in patients following major orthopedic surgery was $2.73 \%$, most of them developing DVT within 5 days post operatively. Prophylaxis use decreased incidence but did not completely resolve the problem. In one metaanalysis, it was reported that the incidence of PE within 3 months after the procedure was $3.2 \%$ in patients receiving short-term prophylaxis (7-10 days) ${ }^{9}$. The incidence of DVT in patients who did not received thromboprophylaxis was $16.66 \%$, this rate is lower than the reported rates $(40-60 \%)^{\mathbf{1 0}}$, the reason may was the majority of them presented with no additional risk except the risk of surgery only, and the age group was less than 40 years. Our analysis revealed that the patients received general anesthesia $(p=0.012)$ were at a greater risk for the development of DVT than those who had spinal anesthesia, this found to be complied with a meta-analysis conducted by $\mathrm{Hu}$ et al., of 21 randomized clinical trial and the result was that compared with general and local anesthesia for total knee replacement (TKR) or total hip replacement (THR) was associated with a reduced incidence of both DVT and $\mathrm{PE}^{8}$. Even in high risk groups, in all the hospitals included in the sample, there were no special considerations regarding method, choice of drug or the duration of thromboprophylaxis. No method for patients risk stratification was implemented to assess the cases. With regards to method and time of thromoboprophylaxis initiation after major orthopedic surgery, the practice of the hospitals was inconsistent with the ACCP recommendations and inconsistent with regard to extend the duration of thromboprophylaxis especially in high risk patients, most of hospitals in this study administered thromboprophylaxis for 3-5 days only.

\section{CONCLUSION}

The incidence of venous thromboembolism in patients following major orthopedic surgery was $2.73 \%$, most of them developing DVT within 5 days post operatively despite the use of mechanical interventions and pharmacological prophylaxis, venous thromboembolism is an important complication of major orthopedic surgery, and the risk is higher in: Patients who aged $\geq 60$ years, Diabetic patients, hypertensive patients, patients received short term thromboprophylaxis $<14$ days and Patients whose orthopedic surgery performed under general anesthesia. Clinicians should implement to a risk stratification model and an evidence based protocol and be aware of VTE, especially in elderly patients ( $\geq 60$ years of age) 
who present with comorbidity and extend the thromboprophylaxis duration in the high risk patients.

\section{AUTHOR'S CONTRIBUTION}

The manuscript was carried out, written, and approved in collaboration with all authors.

\section{ACKNOWLEDGEMENTS}

The authors extend their thanks and appreciation to the Napata College, Khartoum, Sudan to provide necessary facilities for this work.

\section{CONFLICT OF INTEREST}

No conflict of interest associated with this work.

\section{REFERENCES}

1. Sors $\mathrm{H}$, Meyer G. Place of aspirin in prophylaxis of venous thromboembolism. Lancet 2000;355 (9212):12889. https://doi.org/10.1016/S0140-6736(00)02104-8

2. Prevention of pulmonary embolism and deep vein thrombosis with low dose aspirin: Pulmonary Embolism Prevention (PEP) trial. Lancet 2000; 355 (9212):1295-302. PMID: 10776741

3. David A Forsh, MD; Chief Editor: Harris Gellman, Deep Venous Thrombosis Prophylaxis in Orthopedic Surgery, https://emedicine.medscape.com/article/1268573overview\#aw2aab6b3

4. Kakkar AK, Sophie K, Smith R. Incidence of venous thromboembolism in orthopedic surgery, thromboembolism in orthopedic surgery, Liau 2013;978-1-44714335-2.https://doi.org/10.1007/978-1-4471-4336-9_2
5. Joseph A, Caprini, et al. Update on risk factors for venous thromboembolism. The American J Med, an Elsevier, May 2005, 3-9.

6. Guyatt HG, Akl EA, Crowther M, et al. Executive Summary: Antithrombotic Therapy and Prevention of Thrombosis, $9^{\text {th }}$ ed: American College of Chest Physicians Evidence-Based Clinical Practice Guidelines, Chest 2012; 141(2)(suppl):7S-47S. https://doi.org/10.1378/chest.1412S3

7. Farfan M, Bautista M, Bonilla G, Rojas J, Llinas A, Navas J. Worldwide adherence to ACCP guidelines for thromboprophylaxis after major orthopedic surgery: A systematic review of the literature and meta-analysis. Thrombosis Res J 2016;141:163-170. https://doi.org/10.1016/j.thromres.2016.03.029

8. Hu S, Zhang ZY, Hua YQ, et al. A comparison of regional and general anaesthesia for total replacement of the hip or knee: a meta-analysis. J Bone Joint Surg British 2009; 91:935-42.

https://doi.org/10.1302/0301-620X.91B7.21538

9. Douketis JD, Eikelboom JW, Quinlan DJ, Willan AR, Crowther MA. Short-duration prophylaxis against venous thromboembolism after total hip or knee replacement. A meta-analysis of prospective studies investigating symptomatic outcomes. Ach Intern Med 2002; 162:14651471. https://doi.org/10.1001/archinte.162.13.1465

10. Shannon M, Bates, Roman Jaeschke, Scott M. Stevens et al. Diagnosis of DVT, antithrombotic therapy and prevention of thrombosis. $9^{\text {th }}$ ed: American College of Chest Physicians Evidence-Based Clinical Practice Guidelines. Chest 2012; 141(2 Suppl): e351S-e418S https://doi.org/10.1378/chest.11-2299 